\title{
Terra, teto e trabalho: Direitos Humanos e a Doutrina Social da Igreja a partir do Papa Franciseo
}

\section{Land, housing and work: Human Rights and the Church's Social Doctrine from Pope Francis}

\author{
Robson Ribeiro de Oliveira Castro Chaves* \\ ITF
}

Recebido em: 23/02/2021. Aceito em: 15/03/2021.

Resumo: O presente artigo visa analisar os discursos do Papa Francisco em seu pontificado e sua proposta de atualização da Doutrina Social da Igreja à nossa realidade. Buscar-se-ão em seus pronunciamentos e documentos pontifícios dados pertinentes ao tema e seus desdobramentos no campo ético-político-social atrelando esta realidade aos direitos humanos. Analisar-se-á o tema Terra, Teto e Trabalho - os três T's - e suas realidades na Igreja, na sociedade e no desenvolvimento humano integral. Buscar-se-á, ainda, refletir sobre a realidade da economia capitalista que não colabora para o desenvolvimento humano. $O$ capitalismo atual que mata e legitima uma competição desenfreada em prol do lucro. Assim, frente aos dados apresentados, observar-se-á a relação do indivíduo com a economia, sua afinidade e dependência do sistema capitalista. Por fim, apresentar-se-á a relação do Papa Francisco e os direitos humanos e seu papel primordial para com os mais frágeis e desfavorecidos.

Palavras-chave: Doutrina Social da Igreja. Direitos Humanos. Papa Francisco. Terra. Trabalho.

Abstract: This article aims to analyze Pope Francis'speeches in his pontificate and his proposal to update the Church's social doctrine to our reality. It will seek in its pronouncements and pontifical documents relevant data to the theme and its developments in the ethical-political-social field, linking this reality to human

* Mestre em Teologia Moral (Faculdade Jesuíta de Filosofia e Teologia - FAJE, Belo Horizonte, 2017). Pós-Graduado em Direito Matrimonial Canônico (Faculdade São Bento do Rio de Janeiro - FSB-RJ, 2012). Graduado em História (Centro de Ensino Superior de Juiz de Fora - CES-JF, Juiz de Fora, 2011). Professor de Teologia Moral no Instituto Teológico Franciscano de Petrópolis (ITF).

E-mail: robsonrcastro@yahoo.com.br. 
rights. The topic of Land, Housing and Work - in Portuguese, these three words begins with " $T$ " and thats why we will refer to them as the three " $T$ " - and their realities in the Church, society and integral human development will be analyzed. We will also seek to reflect on the reality of the capitalist economy that does not contribute to human development. Current capitalism that kills and legitimizes unbridled competition for profit. Thus, in view of the data presented, the individual's relationship with the economy, his affinity and dependence on the capitalist system will be observed. Finally, Pope Francis' relationship with human rights and his primary role towards the most fragile and disadvantaged will be presented.

Keywords: Social Doctrine of the Church. Human rights. Pope Francis. Land. Job.

\section{Introdução}

Desde o início do seu pontificado, Papa Francisco demonstrou uma empatia com os mais simples e humildes. Rejeitando grandes adornos e regalias, desejou uma Igreja pobre para os pobres. Sua intenção sempre foi, desde sua nomeação à cátedra de Pedro, agir em comunhão com a comunidade, além de se colocar a serviço de todos e todas.

De fato, sua atuação e motivação estão cada vez mais latentes em seus pronunciamentos e ações. Neste texto, analisaremos seus pronunciamentos e suas realidades frente aos menos favorecidos, bem como a busca por igualdade de condição de vida e oportunidade.

Sua preocupação com aquilo que é valorizado na relação humana emerge em uma sociedade pautada pelo individualismo e pela cultura do descartável, que faz com que o ser humano seja um mero objeto. Ao elaborar este artigo, colocaremos em pauta a ética teológica e seus desdobramentos no caminho feito por Francisco em seus pronunciamentos e documentos, tendo como plano de fundo a relação humana e condição de uma propriedade privada com terra, teto e trabalho.

Desta maneira, uma análise ética se faz necessária para observar o posicionamento do indivíduo frente as mais diversas desigualdades e desafios. A ética - o agir frente as situações mais complexas - convidando-nos a olhar para o Evangelho e para o Cristo, como exemplo a ser seguido. Para tanto, buscaremos propor uma análise da atual realidade e da ação do cristão frente ao individualismo. 
Apresentaremos alocuções e mensagens do Papa Francisco, seu posicionamento e suas admoestações quanto às violações aos direitos humanos na sociedade atual que ferem a dignidade humana e a moral.

Observaremos que a moral não limita o ser humano ou a sua liberdade mas, norteia as ações e o pensamento focando em uma atitude mais humana. Procuraremos apresentar ações pautadas na ética teológica e na relação com os irmãos, uma vez que Francisco se mostra atento aos desafios e trata a todos de igual maneira. Por fim, buscaremos pensar as ações de forma mais humana e solidária, atenta às necessidades do próximo, evitando, portanto, a cultura do descartável que promove a destruição do ser humano.

\section{O ser humano e sua condição no mundo}

O ser humano, imagem e semelhança de Deus, é o princípio bíblico que observamos no livro do Gênesis. Para tanto, pensar a humanidade sendo semelhante a Deus é o fim último dos direitos humanos e das relações entre os indivíduos. Francisco, preocupado quanto à exclusão social, assevera quanto a luta por direitos e o "reconhecimento de uma lei moral inscrita na própria natureza humana, que inclui a distinção natural entre homem e mulher e o respeito absoluto da vida em todas as suas fases e dimensões."

Há, cada vez mais, uma globalização individualista, a partir da qual se procura apenas o interesse pessoal que degrada a relação humana, gerando a escravização e a desonestidade. A ganância e o desejo por poder e enriquecimento, juntamente com a desvalorização do ser humano e de sua dignidade, são atributos cada vez mais cultuados hoje.

Na Carta Encíclica Fratelli Tutti sobre a fraternidade e a amizade social, assinada na cidade de Assis, junto do túmulo de São Francisco, o Papa Francisco afirma: "Desejo ardentemente que, neste tempo que nos cabe viver, reconhecendo a dignidade de cada pessoa humana, possamos fazer renascer, entre todos, um anseio mundial de fraternidade." ${ }^{2}$

FRANCISCO. Viagem Apostólica do Papa Francisco a Cuba, aos Estados Unidos da América e visita à sede da Organização das Nações Unidas. Vaticano, 25 set. 2015b. Disponível em: http://w2.vatican.va/content/francesco/pt/speeches/2015/september/ documents/papa-francesco_20150925_onu-visita.html. Acesso em: 8 jan. 2021.

2 FRANCISCO. Carta Encíclica Fratelli Tutti sobre a fraternidade e a amizade social. Vaticano, 3 out. 2020, n. 8. Disponível em: www.vatican.va/content/francesco/pt/ 
O Compêndio da Doutrina Social da Igreja ${ }^{3}$ alerta para a relação do ser humano com o trabalho e seu real interesse no enriquecimento que o afasta do Reino de Deus e sua justiça.

Jesus ensina aos homens a não se deixarem escravizar pelo trabalho. Eles devem preocupar-se, antes de tudo, com a sua alma; ganhar o mundo o mundo inteiro não é o escopo de sua vida (cf. Mc 8, 36). [...] O trabalho não deve afligir (cf. Mt 6, 25.31.34): preocupado e agitado por muitas coisas, o homem corre o risco de negligenciar o Reino de Deus e a Sua justiça (cf. Mt 6, 33), de que verdadeiramente necessita; tudo mais, inclusive o trabalho, encontra o seu lugar, o seu sentido e o seu valor somente se orientado para esta única coisa necessária, que jamais lhe será tirada (cf. Lc 10, 40-42). ${ }^{4}$

Em consonância a esta realidade, é necessário observar a condição do indivíduo e sua centralidade no projeto de Deus. Na Constituição Pastoral Gaudium et Spes, do Concílio Vaticano II, é possível observar a preocupação com a promoção humana que "deve ser integral, isto é, promover todos os homens e o homem todo"s. No documento conciliar, ainda é afirmado sobre o respeito à dignidade humana e sua vocação integral, pois o ser humano é o "autor, o centro e o fim de toda a vida econômico-social."

Desta forma, é necessário afirmar a opção pela paz, a promoção da justiça e o respeito dos direitos de todo ser humano. Francisco assevera, no primeiro encontro mundial dos movimentos populares, o tema que gerou e ainda gera grandes repercussões: terra, teto e trabalho. ${ }^{7}$

encyclicals/documents/papa-francesco_20201003_enciclica-fratelli-tutti.html. Acesso em: 3 fev. 2021. (Daqui em diante = FT).

3 PONTIFÍCIO CONSELHO “JUSTIÇA E PAZ". Compêndio da Doutrina Social da Igreja. Disponível em: http://www.vatican.va/roman_curia/pontifical_councils/justpeace/ documents/rc_pc_justpeace_doc_20060526_compendio-dott-soc_po.html. Acesso em: 8 jan. 2021. (Daqui em diante $=$ CDSI).

4 CDSI, n. 260.

5 CONSTITUIÇÃO Pastoral Gaudium et spes sobre a Igreja no mundo de hoje. In: COMPÊNDIO DO VATICANO II. Constituições, Decretos, Declarações. Petrópolis: Vozes, 1996. n. 76. (Daqui em diante = GS).

6 GS, n. 63.

7 Cf. FRANCISCO. Discurso aos participantes no $I^{\circ}$ Encontro Mundial dos Movimentos Populares. 28 out. 2014. Disponível em: http://www.vatican.va/content/francesco/pt/ speeches/2014/october/documents/papa-francesco_20141028_incontro-mondiale-movimenti-popolari.html. Acesso em: 8 jan. 2021. 
E continua apresentando a realidade e a condição de seres solidários, atento ao desenvolvimento de todos e não apenas de uma minoria.

É pensar e agir em termos de comunidade, de prioridades da vida de todos sobre a apropriação dos bens por parte de alguns. É também lutar contra as causas estruturais da pobreza, a desigualdade, a falta de trabalho, a terra e a casa, a negação dos direitos sociais e laborais. É fazer face aos efeitos destruidores do império do dinheiro: as deslocações forçadas, as emigrações dolorosas, o tráfico de pessoas, a droga, a guerra, a violência e todas aquelas realidades que muitos de vós suportam e que todos estamos chamados a transformar. A solidariedade, entendida no seu sentido mais profundo, é uma forma de fazer história e é isto que os movimentos populares fazem. ${ }^{8}$

Tal mensagem é tão importante, que Francisco repete-a na Encíclica Fratelli Tutti, pois observa a real necessidade de se falar das fragilidades e dos contextos da atualidade. ${ }^{9}$ Como líder religioso e exercendo sua influência e poder político, não deixa de manifestar a sua preocupação com as relações humanas.

Os termos utilizados pelo Papa Francisco - terra, teto e trabalho - apresentam uma categoria importante para se falar do Reino de Deus. Cristo veio e mostrou o caminho, para a valorização do ser humano. Francisco se preocupa com a dignidade do indivíduo.

O próprio Senhor Jesus, ao curar o leproso, restituir a vista ao cego, sentar-se à mesa com o publicano, poupar a vida da adúltera e convidar a tratar do viandante ferido, fez-nos compreender como cada ser humano, independentemente da sua condição física, espiritual ou social, seja merecedor de respeito e consideração. ${ }^{10}$

Francisco apresenta a realidade de que é imprescindível que o ser humano tenha a capacidade de ter uma ascensão social, conseguindo sua manutenção e a de sua família. "O desenvolvimento humano integral e o pleno exercício da dignidade humana não podem ser impostos; devem

\footnotetext{
FRANCISCO, 2014.

9 Cf. FT, n. 116.

10 FRANCISCO. Discurso ao corpo diplomático acreditado junto da Santa Sé. Vaticano, 08 jan. 2018. Disponível em: https://w2.vatican.va/content/francesco/pt/speeches/2018/ january/documents/papa-francesco_20180108_corpo-diplomatico.html. Acesso em: 8 jan. 2021.
} 
ser construídos e realizados por cada um, por cada família, em comunhão com os outros seres humanos." 11

A casa comum, ambiente em que todos os seres humanos dividem suas vidas, deve ser enaltecida, e não somente isso, também a vida, em qualquer momento ou situação. Ao falar com os líderes na reunião da ONU, Francisco não mede palavras para apontar sua preocupação com a sacralidade da vida humana, pois não raras vezes homens e mulheres "são vistos como descartáveis."12

De fato, é preciso observar a condição do indivíduo frente aos problemas da terra e a desenfreada monopolização. Na obra da criação, o ser humano tem a condição de "guardião da sua obra, confiando-lhe o encargo de a cultivar e proteger" ${ }^{13}$. Neste desdobramento, ao falar sobre a terra, Francisco recorda alguns aspectos importantes e o mais complexo: a fome. Ele não mede as palavras ao afirmar que a especulação "condiciona o preço dos alimentos tratando-os como uma mercadoria qualquer, milhões de pessoas sofrem e morrem de fome. Por outro lado, descartam-se toneladas de alimentos. Isto constitui um verdadeiro escândalo." ${ }^{\prime 14}$

Recentemente, ao apresentar ao mundo a sua nova encíclica, Fratelli Tutti, sobre a fraternidade e amizade e social, Francisco é categórico a dizer que:

Uma terra será fecunda, um povo dará frutos e será capaz de gerar o amanhã apenas na medida em que dá vida a relações de pertença entre os seus membros, na medida em que cria laços de integração entre as gerações e as diferentes comunidades que o compõem, e ainda, na medida em que quebra as espirais que obscurecem os sentidos, afastando-nos sempre uns dos outros. ${ }^{15}$

Seu posicionamento já era evidente ao fazer um clamor aos líderes e sua preocupação está na dignidade humana latino-americana. Ao recordar os famosos três "T's": terra, teto e trabalho, ele afirma que "são

\footnotetext{
11 FRANCISCO, 2015b.

12 FRANCISCO, 2015b

13 FRANCISCO, 2014.

14 FRANCISCO, 2014.

15 FT, n. 53.
} 
direitos sagrados. Vale a pena, vale a pena lutar por eles. Que o clamor dos excluídos seja escutado na América Latina e em toda a terra". ${ }^{16}$

Em desdobramento a esta questão, reafirma uma questão singular sobre a condição humana e faz um apelo: "Reconhecemos nós, de verdade, que as coisas não andam bem num mundo onde há tantos camponeses sem-terra, tantas famílias sem teto, tantos trabalhadores sem direitos, tantas pessoas feridas na sua dignidade?"17

Francisco se preocupa com a cultura do descarte e o individualismo que compromete o desenvolvimento humano. Desta forma, é necessária uma atuação frente aos problemas sociais e as realidades apresentadas. A ética cristã propõe uma atuação do cristão frente aos problemas sociais e o amor pelo próximo.

\section{A ética cristã e os direitos fundamentais}

A competição desenfreada por qualidade de vida a todo custo faz de dos seres humanos, meros fantoches do mercado. A ganância transforma os valores: deixa de pensar nas relações sociais; volta-se o olhar para o enriquecimento material em desvalorização do ser humano. No Compêndio da Doutrina Social da Igreja há uma afirmação importante sobre o tema do trabalho.

O trabalho é essencial enquanto representa a condição que torna possivel a fundação de uma família, cujos meios de subsistência se obtêm mediante o trabalho. $O$ trabalho condiciona também o processo de crescimento das pessoas, pois uma família vítima do desemprego corre o risco de não realizar plenamente as suas finalidades. ${ }^{18}$

Papa Francisco apresenta um desejo de sonhar com uma Europa mais humana e atenta a todos, que cuida de todos. Com relação às famí-

\footnotetext{
16 FRANCISCO. Discurso aos participantes no $2^{\circ}$ Encontro Mundial dos Movimentos Populares. Vaticano, 09 jul. 2015b. Disponível em: http://w2.vatican.va/content/ francesco/pt/speeches/2015/july/documents/papa-francesco_20150709_bolivia-movimenti-popolari.html. Acesso em: 8 jan. 2021. 
lias, deseja o acolhimento e a dignidade de todos, além de uma sociedade pautada nas relações e não nos números. ${ }^{19}$

Diante dessa análise, é importante observar que este "sonho" pontifício não seria apenas europeu, mas também um sonho de toda a humanidade, que necessita abrir-se ao próximo, colocar-se em serviço para que haja um crescimento para toda a sociedade e seus membros. $\mathrm{O}$ tema da casa é o segundo que Francisco se dedica ao afirmar a importância da moradia e de uma casa para cada família.

Todo ser humano é sujeito de sua vida e tem a mesma dignidade. Cristo é o modelo a ser seguido, Ele se fez humilde e apresentou o Rosto Misericordioso de Deus. Assim, figura de menino Jesus que nasceu em um estábulo, entra em contraste dos grandes prédios e casas luxuosas.

Hoje vivemos em cidades imensas que se mostram modernas, orgulhosas e até vaidosas. Cidades que oferecem numerosos prazeres e bem-estar para uma minoria feliz, mas nega-se uma casa a milhares de vizinhos e irmãos nossos, até crianças, e chamamos-lhes, elegantemente, 'pessoas sem abrigo '.20

A misericórdia de Deus é gratuita, é uma graça que está à disposição de quem se coloca em atitude de dar e pedir o perdão. O Evangelho não muda, mas a conduta do ser humano sim; necessitamos de sair do comodismo e ir ao encontro do outro. No seio da revelação misericordiosa de Deus é que procede a verdadeira ação humana.

A moral cristã abre-se aos problemas sociais e abraça as grandes categorias da modernidade como os Direitos humanos, democracia, liberdade e igualdade social. As novas perspectivas brotam das bases da Igreja (teólogos, leigos engajados, clero progressista, religiosos, etc.) que, aos poucos, deixam de ser meros porta-vozes de uma hierarquia prisioneira da pré-modernidade. ${ }^{21}$

A fraternidade é a expressão de que pertencemos a uma única família. "O mundo existe para todos, porque todos nós, seres humanos,

19 Cf. FRANCISCO. Entrega do prêmio Carlos Magno. Disponível em: http://w2.vatican. $\mathrm{va} /$ content/francesco/pt/speeches/2016/may/documents/papa-francesco_20160506_ premio-carlo-magno.html\#_ftnref9. Acesso em: 8 jan. 2021.

20 FRANCISCO, 2014.

21 GASDA, E. Política, cristianismo e laicidade. Perspectiva Teológica, Belo Horizonte, v. 47, n. 132, Maio/Ago. 2015, p. 211. 
nascemos nesta terra com a mesma dignidade." 22 A verdadeira atitude evangélica se faz no reconhecimento da dignidade do outro. "O cristão jamais pode permitir que pessoas sejam descartadas. Todo o Ensino Social da Igreja está apoiado no princípio permanente da dignidade humana."23

O julgamento deve dar lugar à consciência cristã de somos filhos de Deus. Na realidade atual da sociedade, a ética cristã se propõe a analisar a situação e apresentar uma verdadeira mudança de comportamento. Francisco, em seu discurso na ONU em 2015, assevera que a exclusão social não é o único problema, mas também a exclusão econômica. Esta exclusão corrobora com a ausência da fraternidade. Francisco acrescenta que os mais pobres sofrem e, como consequências, são "descartados pela sociedade, ao mesmo tempo são obrigados a viver de desperdícios. ${ }^{" 24}$

O respeito pela pessoa humana e os seus direitos caminham juntos na necessidade de se repensar as estruturas econômicas, fugindo de uma economia líquida, como afirma Francisco, que só atende às necessidades de alguns e corrobora com a corrupção, para uma economia social, que garanta o direito de terra, trabalho e casa para todos. ${ }^{25}$

Destarte a valorização da vida, a superação das violações da dignidade e dos direitos humanos são realidades de uma autêntica ação ética. Decorre daí, como consequência ética, que a dignidade e todos os seus direitos devem ser reconhecidos em cada ser humano, pois são anteriores à sociedade e se impõem a ela.

Na Encíclica Fratelli Tutti, Francisco continua, ao recordar o tema dos três T's: "É possível desejar um planeta que garanta terra, teto e trabalho para todos. Este é o verdadeiro caminho da paz, e não a estratégia insensata e míope de semear medo e desconfiança perante ameaças externas." 26

A desigualdade social é um problema grave na sociedade, Deus criou o mundo para todos. Jesus veio para assumir o projeto do Pai e foi um defensor da igualdade para todos os homens e mulheres. Por isso, é

\footnotetext{
$22 \quad$ FT, n. 118.

GASDA, E. Deus é Princípio e Fundamento dos Direitos Humanos. Dom Total, 08 dez. 2017. Disponível em: http://domtotal.com/noticia/1214187/2017/12/deus-e-principio-e-fundamento-dos-direitos-humanos/. Acesso em: 8 jan. 2021.

FT, n. 127.
} 
determinante que a sociedade consiga entender que todos têm o mesmo direito e, como Francisco afirma, não pode haver divisões ou privilégios.

As diferenças de cor, religião, capacidade, local de nascimento, lugar de residência e muitas outras não podem antepor-se nem ser usadas para justificar privilégios de alguns em detrimento dos direitos de todos. Por conseguinte, como comunidade, temos o dever de garantir que cada pessoa viva com dignidade e disponha de adequadas oportunidades para o seu desenvolvimento integral. ${ }^{27}$

A condição atual incomoda e trata o ser humano como mero objeto, muitas vezes desrespeitado em sua essência como ser querido e amado por Deus, mas somente mais um membro que produz e leva lucro e garantias para a sociedade desumanizada. ${ }^{28}$

De forma concreta e bem atuante, é preciso observar o que a economia faz com a sociedade e com os indivíduos: "A economia não deveria ser um mecanismo de acumulação, mas a condigna administração da casa comum. Isto implica cuidar zelosamente da casa e distribuir adequadamente os bens entre todos". ${ }^{29}$

Francisco apresenta a expressão Igreja em saída, como uma condição primeira para sair do fechamento e ir ao encontro dos que mais necessitam. É necessário tomar a iniciativa e sem medo buscar os afastados e convidar os excluídos para participar. ${ }^{30}$

Para tanto, uma Igreja em saída, atua na comunidade, assim, Francisco, atento às realidades do povo, se preocupado com a condição missionária, além de uma Igreja aberta que se coloca no caminho e vai ao encontro dos marginalizados:

prefiro uma Igreja acidentada, ferida e enlameada por ter saído pelas estradas, a uma Igreja enferma pelo fechamento e a comodidade de se agarrar às próprias seguranças. Não quero uma Igreja preocupada com ser o centro, e que acaba presa num emaranhado de obsessões e procedimentos. Se alguma coisa nos deve santamente inquietar e preocupar a nossa consciência é que haja tantos irmãos nossos que vivem

$27 \quad$ FT, n. 118.

28 Cf. FRANCISCO. Exortação Apostólica Evangelii Gaudium. São Paulo: Loyola, 2013, n. 224. (Daqui em diante $=E G$ ).

29 FRANCISCO, 2015a, n. 3.

30 Cf. EG, n. 24. 
sem a força, a luz e a consolação da amizade com Jesus Cristo, sem uma comunidade de fé que os acolha, sem um horizonte de sentido e de vida. Mais do que o temor de falhar, espero que nos mova o medo de nos encerrarmos nas estruturas que nos dão uma falsa proteção, nas normas que nos transformam em juizes implacáveis, nos hábitos em que nos sentimos tranquilos, enquanto lá fora há uma multidão faminta e Jesus repete-nos sem cessar: "Dai-lhes vós mesmos de comer" (Mc 6, 37). ${ }^{31}$

O princípio da ação e da ética cristã é a caridade, para tanto, é necessário enaltecer as relações humanas e proporcionar uma igualdade entre todos. O ser humano se apega aos bens materiais e é nesta relação que há uma inversão dos valores éticos e morais. A caridade tem sua tradução na solidariedade, sendo esta última o bem primordial do ser humano que é a dignidade humana.

Deus não quer que nenhum de seus filhos sofra por não ter condições de viver com dignidade. A caridade é base de uma ética-teológica, porém é necessário haver uma renovação neste pensamento. Como Francisco assevera ao observar a realidade dos direitos sagrados de cada ser humano.

\section{Francisco e os Direitos Humanos}

Francisco, desde sua eleição como Sucessor de Pedro, deseja uma Igreja deportas abertas e pronta a dialogar. Por isso, Francisco atento às desigualdades é contundente e não aceita uma economia de exclusão e a idolatria do dinheiro.

O ser humano é um ser sociável e, por assim ser, promove sua relação com os outros. Nunca estando sozinho, vive em família e em sociedade, participa da criação e é corresponsável por ela. Entretanto, a sociedade, com sua disputa por melhoria de vida e bens de consumo, faz do ser humano um escravo de sua necessidade, principalmente com a desvalorização do trabalho.

Francisco é crítico e alerta sobre a cultura do descarte e a desvalorização dos direitos humanos, quando na economia está o deus dinheiro como centro e não o ser humano, havendo assim uma inversão de valores. ${ }^{32}$

\footnotetext{
31 EG, n. 49.

32 FRANCISCO, 2014.
} 
Com esta dura realidade do descarte, Francisco deseja um mundo mais igualitário, sem ideologias, onde homens e mulheres busquem a fraternidade e o apoio em Deus. Ele recorda que é necessário plantar um tempo de mudança, para que se possa haver uma boa colheita no futuro. Sendo assim, assevera sobre a necessária mudança interna e que cada um é responsável por esta transformação, sendo parte de um todo. "Cada um de nós é apenas uma parte de um todo complexo e diversificado interagindo no tempo: povos que lutam por uma afirmação, por um destino, por viver com dignidade, por 'viver bem', dignamente, nesse sentido". ${ }^{33}$

Diante da desvalorização do ser humano e as constantes ameaças a dignidade humana, Francisco se preocupa com a cultura do descartável e alerta para a realidade de exclusão dos indivíduos e a forma como é tratado sendo considerado um bem de consumo, e, caso não haja mais produção, é desprezado como uma sobra. ${ }^{34}$

O Papa mostra à necessidade de se observar a realidade à luz do Evangelho, como no caminho feito pelo Samaritano, ao ajudar aquele que estava caído na beira da estrada. ${ }^{35}$ Francisco afirma que, nesta parábola, o ícone que colabora para o entendimento de uma "opção fundamental que precisamos tomar para reconstruir este mundo que nos está a peito. Diante de tanta dor, à vista de tantas feridas, a única via de saída é ser como o bom samaritano." 36

Como na parábola do Samaritano há uma caminhada; Francisco chama a atenção para o cuidado com o outro, pois havia um homem muito ferido que fora assaltado. Pelo caminho alguns passavam e somente olhavam, não tendo tempo para ajudar, entretanto, ele acrescenta que: "Eram pessoas com funções importantes na sociedade, que não tinham no coração o amor pelo bem comum. Não foram capazes de perder uns minutos para cuidar do ferido ou, pelo menos, procurar ajuda. ${ }^{{ }^{37}}$

Ao continuar a narrativa da parábola, Francisco oferece indicações para refletir sobre a atitude do Samaritano:

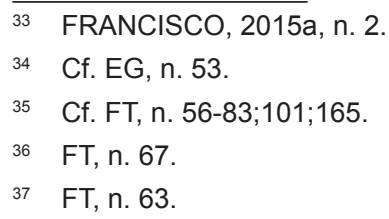


Um parou, ofereceu-lhe proximidade, curou-o com as próprias mãos, pôs também dinheiro do seu bolso e ocupou-se dele. Sobretudo deu-lhe algo que, neste mundo apressado, regateamos tanto: deu-lhe o seu tempo. Tinha certamente os seus planos para aproveitar aquele dia a bem das suas necessidades, compromissos ou desejos. Mas conseguiu deixar tudo de lado à vista do ferido e, sem o conhecer, considerou-o digno de lhe dedicar o seu tempo. ${ }^{38}$

De forma categórica, o Papa faz a pergunta: "Com quem te identificas? É uma pergunta sem rodeios, direta e determinante: a qual deles te assemelhas?" 39 Tal questionamento coloca à prova e reflete sobre nossa conduta moral. Desta forma devemos reconhecer a necessidade de lutar pelos mais frágeis e descartados da sociedade. Para Francisco a sociedade precisa ser curada e olhar para os que estão caídos à beira do caminho. "Habituamo-nos a olhar para o outro lado, passar à margem, ignorar as situações até elas nos caírem diretamente em cima." ${ }^{\prime 40}$ E assevera quando cobra das autoridades que cada trabalhador tenha o direito a uma remuneração digna, à segurança social e a aposentadoria. ${ }^{41}$

Para tanto, é urgente observar a escolha feita pelo Samaritano, sendo que este "partiu sem esperar reconhecimentos nem obrigados. A dedicação ao serviço era a grande satisfação diante do seu Deus e na própria vida e, consequentemente, um dever. ${ }^{" 42}$ Francisco se aproxima dos mais pobres e vive em prol deles, como o Santo de Assis. Ele expõe o seu desejo de que 'Toquemos a miséria humana, que toquemos a carne sofredora dos outros." ${ }^{43}$

Sendo assim, mais do que nunca, a luta pelos direitos humanos ocorre a cada dia. A proposta de Francisco e da Igreja é uma sociedade igualitária, além do respeito a todos e a promoção da dignidade. Sobre a passagem bíblica do Samaritano ele afirma:

Todos temos uma responsabilidade pelo ferido, que é o nosso povo e todos os povos da terra. Cuidemos da fragilidade de cada homem, cada mulher,

\footnotetext{
FT, n. 63.

FT, n. 64.

FT, n. 64.

Cf. FRANCISCO, 2014.

FT, n. 79.

EG, n. 270.
} 
cada criança e cada idoso, com a mesma atitude solidária e solícita, a mesma atitude de proximidade do bom samaritano. ${ }^{44}$

Todos os homens e mulheres devem defender a igualdade e, principalmente, a dignidade humana. Para tanto, o Bispo de Roma assinala que é necessário ter os três " $T$ " - terra, teto e trabalho -, e que nunca deve ser negligenciado o direito a cada um desses aspectos da vida, pois não pode haver uma escravização do ser humano, nem a supremacia de um sobre o outro.

A relação humana deve se voltar para uma vivência cristã pautada no próximo. O Papa se condói daqueles que são escravizados e alerta para a realidade dos que sofrem diante da desigualdade. "O pensamento social do Papa Francisco parece mover-se dentro da perspectiva da igualdade de condições, pois o Pontífice não se cansa de denunciar o sistema econômico como sendo perverso e gerador da desigualdade." ${ }^{45}$

Ao se colocar em serviço, o ser humano se preocupa mais com o outro e vive em comunhão numa relação solidária, atento às necessidades do próximo. A busca sempre se pautará na relação pessoal com o outro; procurar viver como irmãos, em um mundo mais humano e com relações mais próximas e harmoniosas.

Francisco alerta para a cultura do ódio e da vingança que compromete diretamente o bem da sociedade. De fato, pra ocorrer a transformação necessária é importante haver uma maior valorização da vida, na participação no desenvolvimento político-social e no combate à desigualdade econômica.

Nessa ótica é necessário buscar atitudes éticas para que se possa vivenciar uma relação em busca da misericórdia e a igualdade para todos, pois

O futuro da humanidade não está unicamente nas mãos dos grandes dirigentes, das grandes potências e das elites. Está fundamentalmente nas mãos dos povos; na sua capacidade de se organizarem e também nas suas mãos que regem, com humildade e convicção, este processo de mudança. ${ }^{46}$

44 FT, n. 79.

45 ALVES, Antonio Aparecido. A Doutrina Social do Papa Francisco. Revista TheAR Theologia e Assuntos Religiosos, n. 7, 2019, p. 11. Disponível em: http://revistathear. emnuvens.com.br/rttar/article/view/45. Acesso em: 11 jan. 2021.

46 FRANCISCO, 2015a, n. 4. 
Não é possível aceitar uma sociedade voltada somente para o lucro e enriquecimento, sem antes pensar na realidade. O ser humano não pode ser taxado como apenas número. Assim, pensar na Doutrina Social da Igreja no pontificado do Papa Francisco é promover uma ética teológico-cristã, encarnada na vivência cotidiana, pautada na acolhida e no respeito humano, inspirada na misericórdia divina.

\section{Considerações finais}

Ao analisar o pontificado do Papa Francisco e sua preocupação com os Direitos humanos e os desdobramentos da Doutrina Social da Igreja, principalmente no que ele apresenta sobre os três " $T$ " - terra, teto e trabalho-, observarmos que seu desejo é, acima de tudo, o ser humano e sua dignidade.

É necessário se humanizar, promover uma sociedade mais humana e, acima de tudo, ações éticas pautadas na vivência cristã, tão esquecidas nos dias de hoje e que são tão urgentes. Não se pode compactuar com a desvalorização dos indivíduos, principalmente com a manipulação e propostas que vão contra o diálogo e a igualdade. Assim também é importante crescer a experiência de uma Igreja mais próxima dos que mais precisam, dos que estão à margem da sociedade e nas periferias, sofrendo com as carências e mazelas da desigualdade.

Francisco se empenha em falar dos direitos humanos preocupado com a cultura do descartável e com as violações existentes; ele expressa seu desejo de que a Igreja seja uma casa paterna de portas abertas para acolher o próximo. Destarte, a vida humana deve ser sempre respeitada, independentemente de sua situação. Há uma necessidade ardente para que se conscientize sobre a realidade que se vive.

O Evangelho é o centro de toda ação da ética cristã, pois a pessoa humana, imagem e semelhança de Deus, é dotada de todo o bem do próprio criador. Francisco se preocupa com seu povo, com os mais necessitados e que vivem nas periferias; não deseja que o povo tenha divisões e sonha com uma sociedade mais humana e mais unida. Francisco aproxima-se das pessoas, não teme tocá-las, como o Samaritano que acolheu o ferido e curou suas feridas. 


\section{Referências}

ALVES, Antonio Aparecido. A Doutrina Social do Papa Francisco. Revista TheAR Theologia e Assuntos Religiosos, n. 7, 2019, p. 4-17. Disponível em: http://revistathear.emnuvens.com.br/rttar/article/view/45. Acesso em: 11 jan. 2021.

BÍBLIA DE JERUSALÉM. São Paulo: Paulus, 2002.

CONSTITUIÇÃO Pastoral Gaudium et spes sobre a Igreja no mundo de hoje. In: COMPÊNDIO DO VATICANO II. Constituições, Decretos, Declarações. Petrópolis: Vozes, 1996. p. 141-256. (GS)

FRANCISCO. Exortação Apostólica Evangelii Gaudium. Sobre o anúncio do Evangelho no mundo atual. São Paulo: Loyola, 2013. (EG).

FRANCISCO. Discurso aos participantes no $I^{o}$ Encontro Mundial dos Movimentos Populares. Vaticano, 28 out. 2014. Disponível em: http:// www.vatican.va/content/francesco/pt/speeches/2014/october/documents/ papa-francesco_20141028_incontro-mondiale-movimenti-popolari.html. Acesso em: 8 jan. 2021.

FRANCISCO. Discurso aos participantes no $2^{\circ}$ Encontro Mundial dos Movimentos Populares. Vaticano, 9 jul. 2015a. Disponível em: http:// w2.vatican.va/content/francesco/pt/speeches/2015/july/documents/ papa-francesco_20150709_bolivia-movimenti-popolari.html. Acesso em: 8 jan. 2021.

FRANCISCO. Viagem Apostólica do Papa Francisco a Cuba, aos Estados Unidos da América e visita à sede da Organização das Nações Unidas. Vaticano, 25 set. 2015b. Disponível em: http://w2.vatican.va/ content/francesco/pt/speeches/2015/september/documents/papa-francesco_20150925_onu-visita.html. Acesso em: 8 jan. 2021.

FRANCISCO. Entrega do prêmio Carlos Magno. Vaticano, 6 maio 2016. Disponível em: http://w2.vatican.va/content/francesco/pt/speeches/2016/ may/documents/papa-francesco_20160506_premio-carlo-magno. html\#_ftnref9. Acesso em: 8 jan. 2021.

FRANCISCO. Discurso ao corpo diplomático acreditado junto da Santa Sé. Vaticano, 8 jan. 2018. Disponível em: https://w2.vatican.va/ content/francesco/pt/speeches/2018/january/documents/papa-francesco_20180108_corpo-diplomatico.html. Acesso em: 8 jan. 2021. 
FRANCISCO. Carta Encíclica Fratelli Tutti sobre a fraternidade e a amizade social. Vaticano, 3 out. 2020. Disponível em: www.vatican.va/ content/francesco/pt/encyclicals/documents/papa-francesco_20201003_ enciclica-fratelli-tutti.html. Acesso em: 3 fev. 2021. (FT).

GASDA, E. Política, cristianismo e laicidade. Perspectiva Teológica, Belo horizonte, v. 47, n. 132, p. 203-220, maio/ago. 2015.

FRANCISCO. Deus é Princípio e Fundamento dos Direitos Humanos. Dom Total, 8 dez. 2017. Disponível em: http://domtotal.com/ noticia/1214187/2017/12/deus-e-principio-e-fundamento-dos-direitos-humanos/. Acesso em: 8 jan. 2021.

PONTIFÍCIO CONSELHO “JUSTIÇA E PAZ". Compêndio da Doutrina Social da Igreja. Disponível em: http://www.vatican.va/ roman_curia/pontifical_councils/justpeace/documents/rc_pc_justpeace_doc_20060526_compendio-dott-soc_po.html. Acesso em: 8 jan. 2021. (CDSI). 